\title{
Formação continuada docente e desigualdade educacional em tempos de pandemia no estado de Mato Grosso
}

\author{
Michael Douglas Rodrigues \\ Universidade Estadual de Goiás \\ soumichael1@gmail.com \\ https://orcid.org/0000-0003-1507-8591 \\ Pricila Cabral Coelho Moraes \\ Universidade Estadual de Goiás \\ pricilacabral@hotmail.com \\ https://orcid.org/0000-0002-2421-6944 \\ Viviane Pires Viana Silvestre \\ Universidade Estadual de Goiás \\ vivianepvs@gmail.com \\ https://orcid.org/0000-0003-2234-9046
}

RESUMO: Objetivamos problematizar a relação entre as expectativas de professoras/es participantes de uma experiência de formação continuada docente promovida pela SEDUC-MT nos meses de maio e junho de 2020, de modo remoto, com foco em metodologias ativas, e as realidades de desigualdade educacional que se exacerbaram em um cenário de pandemia global-local. O material empírico deste estudo constitui-se de seis relatos produzidos pelas/os professoras/es como atividade final do curso e do relatório de acessos às contas do Google for Education, referente a maio de 2021, fornecido pela SEDUC-MT. A análise do material empírico aponta que as/os docentes tinham expectativas de retorno às aulas para que pudessem vivenciar o que haviam aprendido no curso. Por outro lado, um ano após a experiência de formação, a realidade que se evidenciou foi de pouca acessibilidade discente, como ilustram os dados do relatório.

PALAVRAS-CHAVE: Expectativa $\mathrm{x}$ realidade. Pandemia de COVID-19. Metodologias ativas. Desigualdade educacional. SEDUC-MT.

\section{IN-SERVICE TEACHER EDUCATION AND EDUCATIONAL INEQUALITY IN PANDEMIC TIMES IN MATO GROSSO}

ABSTRACT: This text aims to problematize the expectations of teachers participating in an inservice teacher education remote experience promoted by SEDUC-MT in May and June 2020, with focus on active methodologies, and the realities of educational inequality that were exacerbated in a global-local pandemic scenario. The empirical material of this study consists of six reports produced by the teachers as the final activity of the course and the report on access to Google for Education accounts in May 2021 provided by SEDUC-MT. The analysis of the empirical material shows that the teachers had expectations of returning to classes so that they could experience what they had learned in the course. On the other hand, one year after the teacher education experience, the reality that emerged was that of poor student accessibility, as illustrated by the data in the report.

KEYWORDS: Expectation vs. reality. COVID-19 pandemic. Active methodologies. Educational inequality. SEDUC-MT. 
É imperioso mantermos a esperança mesmo quando a dureza ou aspereza da realidade sugiram o contrário.

(Paulo Freire em À sombra desta mangueira, 2019 [1995], p. 153)

\section{O TEMIDO VÍRUS CHEGOU - E AGORA?}

As medidas que surgiram com a pandemia de COVID-19 - doença provocada pelo vírus Sars-CoV-2, popularmente conhecido como novo coronavírus - motivaram o surgimento de novas práticas sociais no cotidiano dos seres humanos, em esferas locais e globais, visando o combate à disseminação do vírus, tais como: o uso obrigatório de máscaras, o distanciamento ou o isolamento social e físico, mudanças no funcionamento de instituições comerciais, religiosas, rodoviárias, culturais e educacionais, entre outros estabelecimentos que alteraram suas rotinas. Tais práticas tornaram-se corriqueiras com as declarações oficiais da Organização Mundial da Saúde (OMS) e a classificação de risco mundial de uma pandemia de COVID-19 (WORLD HEALTH ORGANIZATION, 2020). No Brasil, a portaria $n^{\circ} 188$, de 3 de fevereiro de 2020, reforça tais declarações da OMS e oficializa "Emergência de Saúde Pública de Importância Nacional" no Ministério da Saúde. Em momento outro, o estado nacional também publica a portaria $n^{\circ} 356$, respaldada na Lei ${ }^{\circ}$ 13.979, com o intuito de estabelecer "as medidas para enfrentamento da emergência de saúde pública de importância internacional decorrente do coronavírus" (BRASIL, 2020, p. 185). Os documentos destacados, além de outros - nacionais, estaduais ou municipais -, visavam regulamentar e operacionalizar nas mais diversas esferas, práticas de prevenção e de combate à disseminação do coronavírus.

$\mathrm{Na}$ esfera educacional, um estudo realizado entre 30 de abril a 10 de maio de 2020 pelo Departamento de Pesquisas Educacionais da Fundação Carlos Chagas (2020), com apoio da Cátedra da UNESCO em Formação de Professores, aponta uma conjuntura de novas práticas na rotina profissional das/os docentes brasileiras/os. Com a participação de 14.285 professoras/es das 27 unidades federativas, o estudo, no formato de boletim informativo, aponta várias informações, como o aumento na rotina de trabalho das/os professoras/es, principalmente em atividades que envolvem recursos interativos no uso de Tecnologias Digitais de Informação e Comunicação (TDICs). Ainda de acordo com o estudo, constatou-se que $81,9 \%$ das/os estudantes da Educação Básica deixaram de frequentar as instituições de ensino. Este número se aproxima da quantidade de estudantes matriculados na rede pública de Educação Básica.

Com a recomendação de distanciamento social/físico, algumas instituições de ensino anteciparam o período de férias às/aos discentes e docentes, outras suspenderam as atividades por tempo (in)determinado e boa parte adotaram a modalidade de ensino remoto ou à distância. Na Rede Estadual de Ensino de Mato Grosso, devido à greve ocorrida no ano de 2019, o calendário escolar acabou sendo reorganizado e foram feitas duas atribuições: uma específica para as escolas que não aderiram à greve e outra para as escolas que aderiram ao movimento. As escolas que iniciaram as aulas no primeiro calendário (fevereiro) tiveram as aulas suspensas no final de março de 2020; as escolas do 
segundo calendário não chegaram a iniciar o ano letivo, pois o mesmo iria se iniciar em 23 de março daquele ano. Assim, para as duas realidades, naquele momento inicial de pandemia, a decisão tomada foi a suspensão das aulas até julho de $2020^{1}$. Esse cenário fez com que Secretaria de Estado de Educação do Mato Grosso (SEDUC-MT) buscasse alternativas de ensino, assim como novas concepções de aprendizagem, práticas pedagógicas, materiais e recursos digitais, bem como cursos de formação que atendessem, por um lado, às orientações oficiais de distanciamento social/físico e, por outro, ao direito à educação permanente de suas/seus docentes e discentes.

De acordo com Gobatto e Beraldo (2014), estudiosas de políticas públicas no Estado do Mato Grosso, uma das principais fomentações de valorização e incentivo à formação docente no estado se deu com o Decreto Estadual n 2.007 (MATO GROSSO, 1997), que dispõe sobre a criação e implementação dos Centros de Formação e Atualização de Professores (Cefapro/MT). Tais centros, situados em diversas regiões do estado, visam fomentar programas de formação continuada e "auxiliar os profissionais da rede pública de ensino a refletirem sobre a repercussão social de sua prática" (MATO GROSSO, 1998, p. 3). Nos últimos anos, os Cefapros têm dedicado seus esforços na formação continuada das/os professoras/es de todas áreas nas escolas urbanas, rurais e indígenas. Desde sua implantação e implementação, esses centros vêm se expandindo para atender a toda rede estadual de ensino².

Neste estudo, abordamos uma ação de formação continuada do polo Cefapro de Barra do Garças - de grande porte -, tendo em vista que a segunda autora trabalhou em 2020 como formadora no local. Considerando o cenário inicial de pandemia exposto, uma das atividades do Cefapro de Barra do Garças foi a oferta às/aos docentes da rede estadual, de 18 de maio a 05 de junho de 2020, do curso intitulado "Aprendizagem Conectada: formação continuada online para professores"3, que tinha como propósito discutir as metodologias ativas no processo de ensino e aprendizagem. Focalizamos, então, em uma das turmas do referido curso de formação, na qual a segunda autora deste texto atuou como formadora. Assim, ancorados/as na abordagem qualitativa de pesquisa (DENZIN; LINCOLN, 2006) e na análise de conteúdo (CHIZZOTTI, 2011), nosso intuito é problematizar as expectativas de seis docentes participantes desta experiência de formação continuada promovida pela SEDUC-MT no início da pandemia e a realidade educacional na Rede Estadual de Ensino de Mato Grosso um ano após a realização do curso de formação, ainda com a permanência do cenário de pandemia global-local. Nesse sentido, a pergunta que orienta este estudo é: qual a relação entre as expectativas de seis docentes participantes de uma experiência de formação continuada promovida pela

\footnotetext{
1 A retomada das aulas, de maneira remota, na Rede Estadual de Ensino de Mato Grosso se deu a partir de agosto de 2020, por meio da Plataforma Virtual "Aprendizagem Conectada". Disponível em: http://www.aprendizagemconectada.mt.gov.br/https://portal.educacao.go.gov. br Acesso em: 14 jun. 2021.

2 Em 2021, a SEDUC-MT publicou o decreto 823, de 15 de fevereiro de 2021, de caráter transitório, que trata da criação e estruturação das Diretorias Regionais (função acumulada temporariamente pela gestão dos Cefapros).

3 O curso contemplou a carga horária de 24 horas. Sob responsabilidade do Cefapro de Barra do Garças, houve a participação de oitocentos e quarenta e sete (847) professoras/es, de quinze (15) municípios diferentes, tendo dezoito (18) gestoras/es de formação como tutoras/es das turmas. Na turma em foco neste estudo, havia cinquenta (50) docentes inscritas/os, chegando a trinta e oito (38) docentes concluintes.
} 
SEDUC-MT no início da pandemia e a realidade educacional na Rede Estadual de Ensino de MT um ano após a realização do curso? Para tanto, o material empírico analisado neste estudo constitui-se de seis relatos produzidos pelas/os professoras/es como atividade final do curso e do relatório de acessos às contas do Google for Education ${ }^{4}$ referente a maio de 2021 fornecido pela SEDUC-MT.

Assim, antes de direcionarmos nossas reflexões para o material empírico - foco da terceira e quarta seções deste artigo -, acreditamos ser pertinente retomar a literatura que embasa os objetivos e princípios orientadores do curso ofertado, qual seja a formação continuada docente e as metodologias ativas, que abordamos na sequência.

\section{AS DEMANDAS CONTEMPORÂNEAS NA FORMAC̣ÃO CONTINUADA DOCENTE E AS METODOLOGIAS ATIVAS}

Tratar sobre as demandas na educação e na formação docente, em um sentido geral, implica considerar as instituições, organizações e políticas educacionais que sustentam os currículos, os materiais didáticos e as concepções de ensino e aprendizagem; as constantes transformações nas relações, valores e dinâmicas sociais que a escola traz; o sujeito docente, cuja identidade é sócio historicamente construída em meio às diferenças; como também outras representações e transições do ser, agir e fazer docente e discente.

É indubitável que a contemporaneidade, marcada pela globalização e o surgimento das novas tecnologias, faz com que diferentes comunidades humanas (especialmente as urbanas) vivam de maneira acelerada, com fluxos constantes de informações e relações, assim como fluxos interacionais construídos em cenários, até então, inimagináveis. Tudo isso afeta a base da educação e também da formação de professoras/es. De acordo com André (2010), o cenário contemporâneo impeliu modificações no processo de produção de conhecimento sobre a formação docente. Saviani (2007) também chama atenção para uma nova conjuntura paradigmática, a qual é atravessada, sobretudo, por uma volatilidade plural de ideias, conceitos e pensamentos. Essa conjuntura faz pairar, como enfatiza o educador brasileiro, um clima social condicionado pelas demandas da pós-modernidade. Em um sentido contraposicional, ele explica que: "[s]e o moderno liga-se à revolução centrada nas máquinas mecânicas, na conquista do mundo material, na produção de novos objetos, a pós-modernidade centra-se no mundo da comunicação, na informática, nas máquinas eletrônicas, na produção de símbolos" (SAVIANI, 2007, p. 21).

Trazemos essas contribuições para manifestar que o presente estudo flutua nesse cenário, uma vez que o curso de formação continuada que trazemos para discussão tinha como foco as metodologias ativas. Como ressalta Nóvoa (2014, p. 228), "[a] concepção da escola como espaço aberto, em ligação com outras instituições culturais e científicas, e com uma forte presença das comunidades locais, obriga os docentes a redefinir o sentido social do seu trabalho". Somado a isso, entendemos que a formação continuada é profícua para uma produção de compreensões e de conhecimentos sobre as dimensões

4 A partir de fevereiro de 2021, as aulas remotas na Rede Estadual de Ensino de Mato Grosso passaram a ser ofertadas por meio de recursos virtuais educacionais do Google for Education. 
do ser, agir e fazer docente na escola e que, por isso, pode ser um espaço de atualização e promoção de mudanças significativas na práxis educativa. Por intermédio dela, muitas/ os docentes podem não apenas debater temas, refletir sobre conceituações teóricas e problematizar situações cotidianas, mas também ressignificar suas práxis.

Em adição a isso, o educador brasileiro Freire $(1996$, p. 22) argumenta que a prática educativa envolve um processo dialético "entre o fazer e o pensar sobre o fazer" e que, portanto,

na formação permanente dos professores, o momento fundamental é o da reflexão crítica sobre a prática. É pensando criticamente a prática de hoje ou de ontem que se pode melhorar a próxima prática. O próprio discurso teórico, necessário à reflexão crítica, tem de ser tal modo concreto que quase se confunde com a prática. [...]. Por outro lado, quanto mais me assumo como estou assim, mais me torno capaz de mudar, de promover-me, no caso, do estado de curiosidade ingênua para o de curiosidade epistemológica. (FREIRE, 1996, p. 22)

É nesse sentido que consideramos que a ressignificação da práxis docente está intimamente relacionada com a formação continuada, pois dela advém o crescimento da/o professora/r no sentido pessoal e profissional. Essa perspectiva perpassou a proposta do curso ofertado, com foco no aprofundamento sobre as metodologias ativas. Tal conhecimento pedagógico foi a base de estudo e de reflexões desenvolvidas pelas/os professoras/ es no curso, tendo em vista a sua pertinência na futura realidade que as/os professoras/ es vivenciaram no trabalho com o ensino remoto em Mato Grosso em meio ao cenário da pandemia de COVID-19.

De acordo com Moran (2018, p. 4), as metodologias ativas podem ser definidas como "estratégias de ensino centradas na participação efetiva dos estudantes na construção do processo de aprendizagem, de forma flexível, interligada, híbrida". Ou seja, buscam envolver o sujeito em processos pedagógicos que são mais complexos, interativos e instigantes, com o suporte mais atraente de tecnologias de ensino e percepções processuais de avaliação. Sendo assim, propõe-se práticas de ensino e aprendizagem baseadas em investigações, projetos ou problemas, como também em gamificações, hibridizações ou em aulas invertidas.

No final do século XIX, alinhadas ao movimento da Escola Nova europeia e norte-americana, as metodologias ativas almejavam novas práticas de educação das crianças e jovens para aquela sociedade, como repúdio à conformidade e passividade discente. Cabe ressaltar ainda que a teoria educacional de John Dewey e propostas a ela alinhadas - como a Aprendizagem Baseada em Problemas, a Metodologia da Problematização, a Aprendizagem Baseada em Projetos e a Comunidade de Investigação, entre outras exerceram influência na concepção das metodologias ativas.

Assim, as metodologias ativas surgem de um contradiscurso à educação bancária e tecnicista, que concebe a/o aprendiz como um depositário e supõe-se que em algum momento esse investimento gerará lucro. Entretanto, sabemos que o processo educativo não ocorre dessa maneira e que essas concepções apenas ecoam sentidos de uma educação 
tradicional. É nesse contra caminho que as metodologias ativas constroem as suas bases epistemológicas, evidenciando com suas percepções sobre o processo educ(ativo).

Ademais, as metodologias ativas partem do princípio de que a/o aprendiz é o centro do processo de aprendizagem, sendo não mais uma/um expectadora/or, mas ativa/o na construção de conhecimento. À vista disso, a/o professora/or busca envolver a/o estudante em um maior engajamento em uma gama diversificada de atividades (DIESEL; BALDEZ; MARTINS, 2017). Em síntese, como reitera Moran (2018, p. 4),

[a]s metodologias ativas dão ênfase ao papel protagonista do aluno, ao seu envolvimento direto, participativo e reflexivo em todas as etapas do processo, experimentando desenhando, criando com orientação do professor; a aprendizagem híbrida destaca a flexibilidade, a mistura e compartilhamento de espaços, tempos, atividades, materiais, técnicas, e tecnologias que compõem esse processo ativo.

Nesse sentido, as novas tecnologias digitais, as transformações nas concepções e relações sociais e a pluralidade de perspectivas no processo de significação trazem para a educação novas demandas que, por conseguinte, exigem novas práticas da comunidade escolar. Por outro lado, cabe trazer o seguinte alerta do educador português:

No que diz respeito às tecnologias, é evidente que elas fazem parte da cultura digital das sociedades contemporâneas e que seria absurdo que ficassem fora da escola e não fossem utilizadas do ponto de vista pedagógico. Seria impensável. São instrumentos essenciais para as aprendizagens, nas mãos de professores e alunos. Outra coisa bem diferente é imaginar que tudo se passará on-line, à distância, com os gigantes do digital, os GAFAM (Google ${ }^{5}$, Amazon, Facebook, Apple, Microsoft) a tomarem conta da educação, apoiados por grupos privados e fundações que, através de apostilas digitais, controlariam o ensino e as aprendizagens. (NÓVOA, 2020, p. 9)

Assim, somada à formação continuada docente, acreditamos que é necessária a criação de condições de investimento estrutural e de recursos didáticos para que as/os aprendizes possam, de fato, ter acesso a meios diversos para construir conhecimentos. Como ressalta Trezzi $(2021$, p. 2), "o Brasil precisa antes de tudo pensar em uma escola que seja justa e inclusiva, e não apenas contar com mudanças pontuais como a introdução de novas tecnologias". Assim, também as metodologias ativas precisam ser entendidas criticamente, de modo que não acabem acentuando uma visão mercantilista de educação e de formação docente. Recorrendo uma vez mais a Nóvoa (2020, p. 9, ênfase no original), é preciso muita cautela, especialmente no cenário atual, para "não pensar que o futuro da escola passa pelo retraimento ou clausura em espaços domésticos ou privados, através de um uso extensivo da 'aprendizagem a distância". Isso porque "uma orientação deste tipo acentuaria as tendências para considerar os alunos como consumidores/

5 Cabe lembrar que em janeiro de 2021, a SEDUC-MT firmou termo de cooperação com o Google para utilização de seus recursos para educação (Suite for Education). Disponível em: http://www3.seduc.mt.gov.br/-/16221319-seduc-faz-parceria-com-o-google-e-avanca-na-educacao-on-line Acesso em: 15 jun 2021. 
clientes, bem como as lógicas de mercantilização ou comercialização, pondo em causa a educação como um bem público" (NÓVOA, 2020, p. 9).

$\mathrm{Na}$ sequência, discutimos algumas reflexões feitas por docentes da Rede Estadual de Ensino do Mato Grosso no cenário pandêmico ainda inicial.

\section{EXPECTATIVAS DOCENTES NOS MESES INICIAIS DA PANDEMIA: UMA EXPERIÊNCIA DE FORMACุÃO DOCENTE COM FOCO EM METODOLOGIAS ATIVAS}

No cenário inicial da pandemia de COVID-19 no Brasil, sabemos que diversas redes de ensino adotaram, excepcionalmente, o ensino remoto ou a modalidade de ensino a distância, no intuito de manter a educação permanente de crianças, de jovens e de adultas/os. No entanto, isso não aconteceu com um planejamento prévio e sólido, e sim de forma abrupta. De um dia para o outro, as/os professoras/es viram as suas atividades escolares sendo interrompidas, surgindo maiores jornadas de trabalho, as suas ansiedades e dificuldades de concentração e/ou de suas/seus alunas/os aumentarem, entre outros impactos na rotina educacional (FUNDAÇÃO CARLOS CHAGAS, 2020). Muitas/os professoras/es fizeram dos espaços de sua casa, suas tecnologias e suas câmeras, a nova sala de aula. Como uma forma de dar suporte a suas/seus alunas/os, muitas/os buscaram se aperfeiçoar ou mesmo aprender a lidar com os recursos das tecnologias digitais.

Como já mencionado, o presente texto insere-se nessa conjuntura, partindo de uma experiência de formação continuada, realizada totalmente de modo remoto, que tinha como propósito oferecer um apoio teórico e metodológico às/aos professoras/es ao retornarem às aulas na Rede Estadual de Ensino do Mato Grosso. Esse retorno estava previsto para o segundo semestre de 2020 e o curso focalizou as metodologias ativas, seus princípios e sua aplicação no planejamento com o retorno às aulas, especialmente voltado para a plataforma que seria usada. Como proposta de atividade final, as/os docentes produziram um relato reflexivo acerca das discussões feitas no curso e de como planejavam o retorno das aulas. Dentre as/os trinta e oito (38) docentes concluintes do curso, seis (6) procederam anuência na participação deste estudo, sendo 3 homens e 3 mulheres, com idade entre 25 e 52 anos. Todas/os têm licenciaturas nas respectivas áreas, mas apenas dois são docentes efetivos: (1) Ciências Biológicas, (3) Letras e (2) Matemática. Todas/os são lotadas/os no Cefapro de Barra do Garças, mas residem em municípios diferentes. Para resguardar suas identificações, utilizaremos os seguintes codinomes: Gomes, Souza, Santos, Silva, Martins e Ferraz.

Mesmo afastadas/os da escola devido à pandemia, muitas/os sem contrato de trabalho ativo e fragilizadas/os emocionalmente, as/os professoras/es buscaram maneiras de não perder o contato com suas/seus alunas/os, as/os auxiliando no processo de ensino e aprendizagem, ainda que com as escolas fechadas. Em meio a tantas problemáticas, não deixaram de participar da formação continuada, pois acreditavam que essa oportunidade seria primordial para o retorno às aulas de maneira remota emergencial. Consideramos que problemas de conectividade e a falta de prática em utilizar os aplicativos foram as maiores dificuldades nos dois primeiros encontros formativos; a maioria das/ 
os professoras/es utilizaram o celular para acessar as reuniões. No início do curso, foram feitos tutoriais para auxiliá-las/los nesse processo, além de atendimento individual através do WhatsApp. No último encontro, as/os professoras/es fizeram vários relatos orais de como todo o processo da formação foi importante, abordaram os desafios encontrados e algumas/uns disseram ter criado blogs, páginas nas redes sociais e estavam fazendo videoconferência com suas/seus alunas/os.

Entre as reflexões tecidas nos relatos escritos, trazemos inicialmente alguns excertos que versam sobre como o contexto da pandemia de COVID-19 afetou o cotidiano de suas práticas docentes e quais, eventualmente, seriam consideradas e/ou reconfiguradas no retorno às aulas:

O contexto atual se apresenta desafiador em todos os segmentos sociais, com a Educação não poderia ser diferente, requer mudanças e adaptações tanto para os estudantes como para os professores. (SOUZA).

No pós-pandemia, a educação não será mais a mesma. A tendência já era de mudanças há algum tempo. Algumas discussões foram realizadas nas escolas neste sentido. Contudo, paradoxalmente, este período conturbado está servindo para o alinhamento de algumas leituras e orientações, que faz com que a maioria dos profissionais admita a necessidade de mudanças nas metodologias utilizadas no cotidiano escolar. (SANTOS).

Diante do cenário atual, imaginando o retorno às aulas pós-pandemia, analisando as atividades postadas na plataforma "Aprendizagem Conectada", os conteúdos de Matemática que foram trabalhados ao longo das semanas de recesso, pretendo retomar as atividades partindo desse contexto, porém de forma diferenciada, ou seja, utilizando as "metodologias ativas". (MARTINS)

Observamos nos excertos acima que as/os professoras/es refletem como o cenário da pandemia afetou a esfera educacional e apontam para a necessidade de proposições pedagógicas para lidar com as demandas desse cenário. Souza, por exemplo, corrobora essas ideias ao considerar que tanto as/os professoras/es quanto as/os alunas/os precisarão encontrar maneiras adaptativas que atendam aos objetivos de ensino e aprendizagem. Santos, por outro lado, entende que proposições de mudanças já estavam sendo discutidas, mas que, com esse novo cenário, as/os docentes precisaram se aperfeiçoar para lidar com a excepcionalidade da educação remota. Por sua vez, Martins se coloca disposta a utilizar as metodologias ativas, que ela considera uma forma diferenciada de sua prática docente usual, ainda que não explore como pretende fazê-lo.

Já nos excertos a seguir, as/os professoras/es procuram articular o cenário da pandemia com o seu planejamento pedagógico, tornando-o um aliado na busca pela leitura de mundo de suas/seus aprendizes:

Os estudantes retornarão para escola com diferentes experiências vividas durante a pandemia da Covid-19. Com isso, já poderemos considerar que a introdução da aula de Biologia já foi iniciada, mesmo com os estudantes que não desenvolveram as atividades da plataforma, ou aqueles em contexto de inclusão da Educação especial e/ou indígenas em que a Língua Portuguesa é segunda 
língua. Isto porque todos vivenciaram esta realidade na sua própria casa e acompanharam por meio do acesso à televisão, rádio e internet. (SILVA).

No planejamento de Língua Portuguesa, é necessário realizar, primeiramente, um diagnóstico para então dar continuidade. Neste verificar quais estudantes realizaram as atividades, as dificuldades, dúvidas, dar oportunidade para aqueles que não realizaram (com trabalhos em grupo, textos e atividades preparados pelo professor para estudo em casa, etc.). O diagnóstico será feito por meio de rodas de conversa, debates e trabalhos de síntese com mapas conceituais. [...] No projeto, cada estudante pode contribuir de uma forma diferente e devemos respeitar o tempo de aprendizagem de cada um. Os estudantes indígenas em que a Língua Portuguesa é segunda língua teriam um papel fundamental para trazer informações sobre como os indígenas lidaram com a pandemia. (GOMES).

Como narrado nos excertos acima, as/os professoras/es que integram essa pesquisa pretendem trabalhar com o contexto da pandemia utilizando-se de várias estratégias pedagógicas e linguísticas em seus componentes curriculares, de maneira interdisciplinar. Esse trabalho, por sua vez, parte das necessidades, vivências e conhecimentos desenvolvidos pela/o aluna/o nesse cenário, como propõem Silva e Gomes. Em outras palavras, esse trabalho pedagógico parte de uma concepção de que o mundo está na sala de aula e a sala de aula está no mundo, sendo impossível a sua dissociação. Silva e Gomes, como narram nos excertos, caminham para o entendimento de que a "leitura do mundo" antecede a "leitura da palavra", como preconiza Freire (1996). Em suas palavras, "a leitura de mundo do educando significa tomá-la como ponto de partida para a compreensão do papel da curiosidade [...] como um dos impulsos fundantes da produção do conhecimento" (FREIRE, 1996, p. 77). Vale destacar também, nos excertos apresentados, a preocupação das/os professoras/es em desenvolver aprendizagens que considerem as especificidades das comunidades indígenas que participam da escola, entendendo as suas cosmovisões e epistemologias nesse cenário de pandemia. Nos excertos a seguir, as/os professoras/es dão sequência às narrativas de como pretendem articular o cenário da pandemia ao seu planejamento pedagógico:

Diante do contexto da pandemia e da apropriação do conhecimento das metodologias ativas, irei no primeiro momento fazer uma roda de conversa com os alunos sobre o conhecimento deles sobre a pandemia local, regional, no Brasil e no Mundo. [...] No segundo momento, dividir em grupos os temas que podem ser objetos de pesquisas as variáveis que podem ser: Números de pessoas infectadas no mundo e no Brasil; letalidade, e enfrentamento da pandemia que cada país ou continente enfrentaram, medidas de isolamento ou cuidados para conter o vírus e tratamento das pessoas infectadas. [...] Em seguida pedir para elaborarem tabelas, gráficos, slides, pequenos vídeos para apresentação dos resultados e atividades com gráficos que apresentem os conteúdos apresentados no objeto do conhecimento, para analisarem as medidas tomadas em todo o mundo, comprovando como a estatística e dos gráficos das funções exponenciais, serviram e muito na tomada de decisões por governos e entidades engajadas no combate a COVID-19. Fazer os gráficos usando software, ou ferramenta simples do World para a construção dos gráficos. (FERRAZ). 


\begin{abstract}
Outro fator importante a se considerar é a formação continuada dos professores, pois a sala de aula invertida não tira a responsabilidade do educador, pelo contrário, exige um profissional com novas habilidades. Em meio à Pandemia, garantir continuidade nos estudos é um dever do Estado e dos órgãos competentes. A questão que se apresenta como problema é a maneira em que essas ações são desenvolvidas, no caso de Mato Grosso, foi disponibilizada a Plataforma Aprendizagem Conectada com apostilas semanais para que os estudantes acessem em suas casas juntamente com a família criem um ambiente de estudo e desenvolvam as atividades sem a interação com o professor. [...] Utilizar os recursos midiáticos a favor da aprendizagem é sem dúvida uma estratégia que possibilitará a construção do conhecimento de forma dinâmica, real com possibilidades de flexibilização no planejamento rompendo com as práticas tradicionais. Além disso, é uma maneira de delegar autonomia aos estudantes por meio de leituras e pesquisas digitais, garantindo maior capacidade de reflexão sobre o conteúdo a ser trabalhado. [...] Utilizar metodologias ativas com a proposta da sala de aula invertida requer também mudanças e comprometimento de toda equipe escolar em especial da equipe gestora em adequar a estrutura física com equipamentos que permitam maior interatividade de todos. (SOUZA).
\end{abstract}

Considerando os trechos acima, notamos que as/os professoras/es buscaram articular os conhecimentos desenvolvidos no curso de formação com possibilidades pedagógicas em um cenário que, a priori, não aparenta ser propício para esse trabalho. Mesmo com tais adversidades apontadas, observa-se que essas/es professoras/es utilizam desse cenário para criar oportunidades de aprendizagem, não ignorando o contexto, mas tornando-o um motor para possibilitar que a/o aprendiz desenvolva conhecimento que seja compatível com sua realidade. Destaca-se, ainda, a gama de recursos didáticos e gêneros de linguagem que essas/es professoras/es pretendem utilizar, como rodas de conversas, gráficos, tabelas, quer sejam digitais ou não.

Além disso, esses relatos evidenciam uma expectativa de breve retomada das atividades escolares, incluindo aqueles estudantes que, por motivos diversos, não tivessem realizado as atividades disponíveis na plataforma em uso. Em seus relatos, não está evidenciada a falta de conectividade e condições de acesso e desenvolvimento das atividades remotas pelo coletivo discente. Por outro lado, Souza se mostra atenta à necessidade de investimento em infraestrutura para que a proposta enfocada no curso - metodologias ativas - possa se concretizar. Contrariando as expectativas, de certo modo, otimistas das / os docentes naquele momento, "o ano de 2020 foi marcado por uma catástrofe educacional", nas palavras do secretário estadual de educação do Mato Grosso - Alan Porto (A FOLHA, 2021).

\title{
QUEM PODE SER "ATIVA/O" NO ENSINO REMOTO EMERGENCIAL?: A DURA E ÁSPERA REALIDADE DE DESIGUALDADE DE ACESSO À EDUCACุÃO NA REDE PÚBLICA
}

"A Educação pode ser a cicatriz mais duradoura da COVID-19 da América Latina" - escancara a manchete de 03 de dezembro de 2020 do jornal Americas Quartely

6 No original: Back to the 1960s? Education May Be Latin America's Most Lasting Scar from COVID-19. 
(AMERICAS QUARTELY, 2020). São tantas as feridas abertas pela pandemia no Brasil, que ainda não sabemos afirmar se, de fato, a educação será mesmo a cicatriz mais forte. No entanto, não há dúvidas de que o crescente fosso educacional existente entre aquelas/es que podem e as/os que não podem seguir seus estudos têm deixado marcas cruéis na história da Educação brasileira. De acordo com o Boletim Educação - Politicas Sociais: acompanhamento e análise, divulgado pelo Instituto de Pesquisa Econômica Aplicada (IPEA, 2021, p. 16), "[o] crescimento das disparidades socioeconômicas e regionais só será de todo conhecida nos anos por vir, mas, desde já, estas impactam o planejamento e a execução de políticas educacionais em todas as esferas da administração pública". Ainda de acordo com o mesmo estudo:

As circunstâncias geradas pela pandemia, no ambiente escolar, colocaram em relevo as aguçadas desigualdades que representam a marca da sociedade brasileira, ao revelar as diferenças entre gerações de professores para a utilização de tecnologias da informação e comunicação (TICs) e, muito especialmente, entre alunos que, não raro, residem em ambiente mal adaptados às atividades escolares, sem a disponibilidade de equipamentos de telefonia móvel, computacionais ou mesmo de internet via banda larga para ter acesso a esse universo que passou a ser simbionte com o sistema escolar. (IPEA, 2021, p. 1-2)

Nessa esteira, estudo do IBGE aponta que 4,3 milhões de estudantes brasileiras/os entraram na pandemia sem acesso à internet - destas/es, 4,1 milhões estavam matriculadas/os na rede pública de ensino (FOLHA DE SÃO PAULO, 2021). Certamente, parte desse número de excluídas/os do processo educacional fazem parte da rede estadual de Mato Grosso. Em maio de 2021, ou seja, um ano após a experiência de formação continuada docente discutida na seção anterior, mais de 70\% das contas usadas para acesso ao ensino remoto na Rede Estadual de Ensino de Mato Grosso estavam inativas - isso considerando as/os estudantes que tiveram condições de, ao menos, criar suas contas (Imagem 1). Se somássemos ao número daquelas/es estudantes que nem tiveram o primeiro acesso, o número contabilizado dessa exclusão seria ainda maior. $\mathrm{Na}$ imagem 1 , podemos verificar esses números também na capital Cuiabá (82\%) e em Barra do Garças $(67,5 \%)$. 
Imagem 1 - Porcentagem de contas ativas e inativas na plataforma Google for Education (termo de cooperação SEDUC-MT e Google)

Uso das contas Google for Education- Mato Grosso

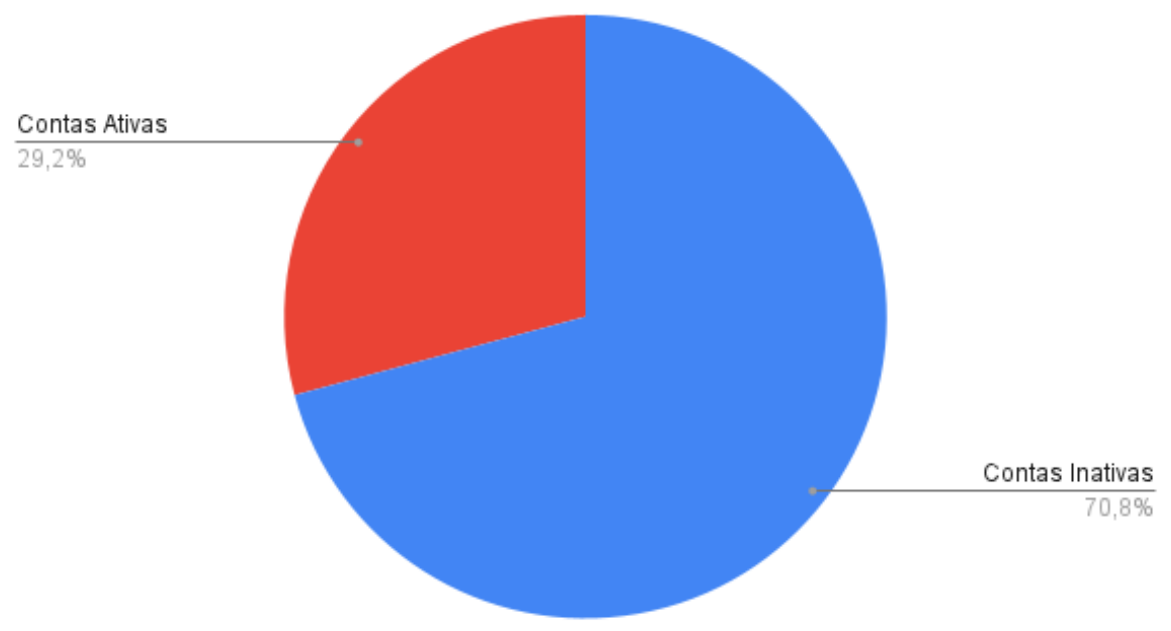

Uso das contas Google for Education- Cuiabá-MT

Contas Ativas

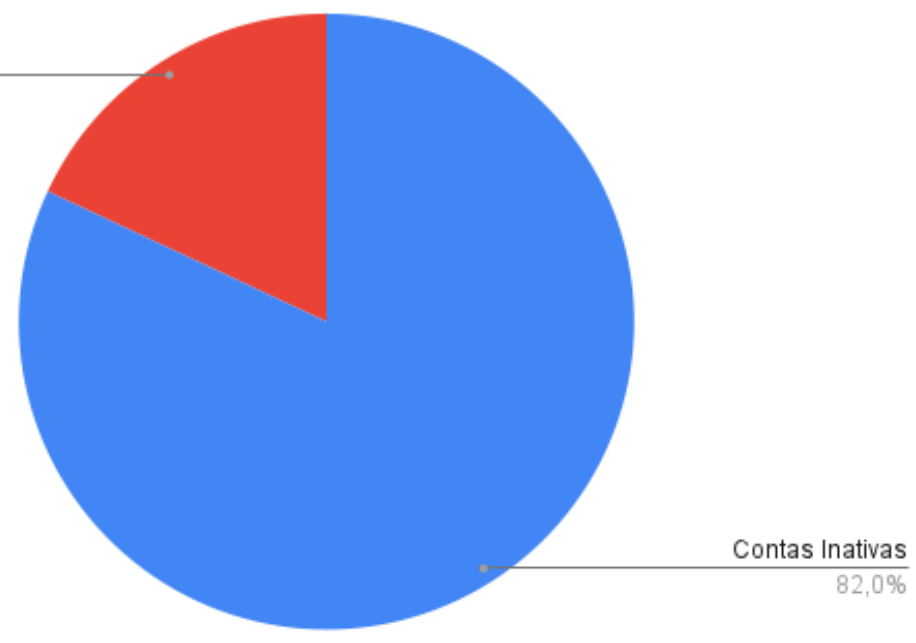

Uso das contas Google for Education- Barra do Garças-MT

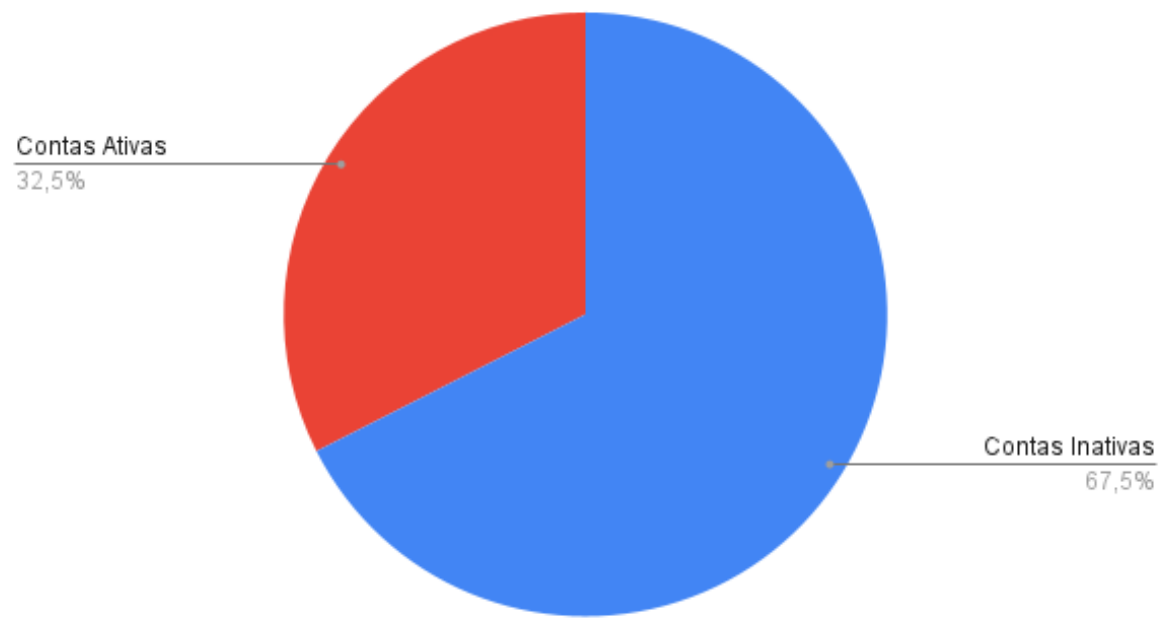

Fonte: Relatório de acessos às contas do Google for Education em maio/2021- SEDUC-MT 
A ausência de políticas de conectividade, aliada à pouca efetividade de políticas já lançadas (BRASIL DE FATO, 2021) contribuem para essa situação deplorável de acessibilidade das/os estudantes da rede pública de ensino. No primeiro semestre de 2021, passados mais de 12 meses do início da pandemia, finalmente a Lei 14.172, de 2021, que garante acesso à internet, com fins educacionais, a alunas/os e professoras/es da educação básica pública foi sancionada. Isso depois de uma longa batalha que contou com voto presidencial ao projeto de lei e seu pedido de recurso ao Supremo Tribunal Federal (STF) - não acatado, felizmente. Agora, por força da lei e a contragosto do presidente Jair Bolsonaro, o governo federal tem até o início de agosto de 2021 para fazer o repasse de $\mathrm{R} \$ 3,5$ bilhões para ações que garantam a conectividade (AGÊNCIA SENADO, 2021).

Sem desmerecer essa importante - apesar de atrasada - conquista, concordamos com Macedo (2021, p. 276) que "é preciso reconhecer que garantir a conectividade para viabilizar o ensino on-line é apenas um paliativo em período de crise, já que o processo de aprendizagem não é só transmissão de conteúdo, mas envolve diversas outras dimensões". O acesso à internet, per se, não garante uma educação justa, inclusiva e de qualidade, como problematiza a charge a seguir (Imagem 2):

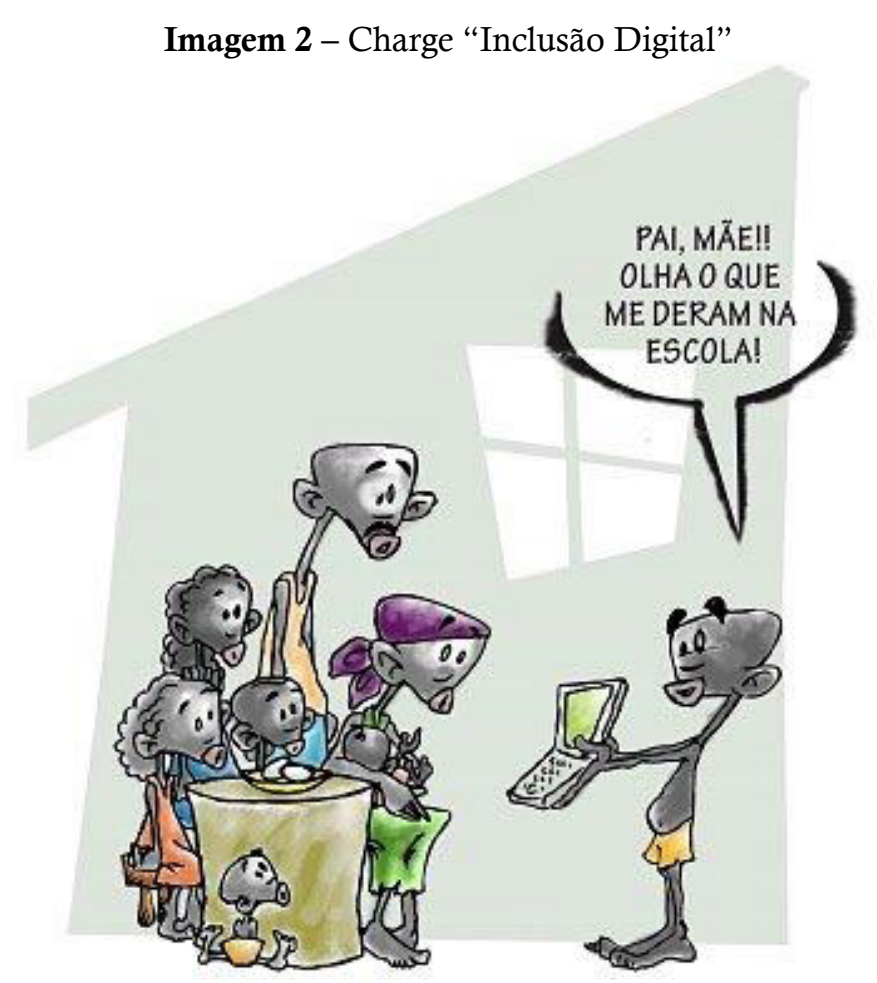

Fonte: https://rizomas.net/images/phocagallery/charges/thumbs/phoca_thumb_1_charge-inclusao-digital.jpg

Por fim, fazemos coro com as palavras de Trezzi (2021, p. 9): “[c]onsidera-se que para uma superação da crise e para focar na possibilidade de a educação não sofrer maiores danos, com o risco do aumento da desigualdade educacional, é preciso que escola passe a ser vista como um espaço de inclusão e não de exclusão". 


\section{INQUIETAÇÕES QUE PERMANECEM}

O presente texto buscou problematizar a relação entre as expectativas de professoras/es participantes de uma experiência de formação continuada docente promovida pela SEDUC-MT nos meses iniciais do cenário de pandemia de COVID-19 - com foco em metodologias ativas - e a realidade de desigualdade educacional que tem se exacerbado cada dia mais desde então. A análise de seis relatos produzidos pelas/os professoras/es como atividade final do curso aponta que as/os docentes tinham expectativas de retorno às aulas para que pudessem vivenciar o que haviam aprendido no curso. Assim, suas expectativas acabaram se mostrando diferentes da dura realidade de desigualdade de acesso às aulas remotas evidenciadas no relatório de acessos às contas do Google for Education de maio de 2021 da SEDUC-MT. Ainda que os excertos analisados assinalem a importância do aprendizado e da troca de experiências nos momentos formativos, no coletivo, assim como o olhar atento a diferentes contextos pelas/os docentes e de como a realidade do ensino remoto exige estratégias e práticas diferentes de ensino, suas reflexões não parecem vislumbrar o cenário catastrófico de inatividade discente que se concretizaria.

Concordamos com Nóvoa (2020, p. 8) quando afirma que "[o]s governos deram respostas frágeis, e as escolas também. As melhores respostas, em todo o mundo, foram dadas por professoras/es que, em colaboração uns com os outros e com as famílias, conseguiram pôr de pé estratégias pedagógicas significativas para este tempo tão difícil". Mesmo em um contexto de sobrecarga emocional e de trabalho, uma parcela significativa de professoras/es têm buscado saídas dentro de suas limitações e possibilidades, quer seja se aperfeiçoando para lidar com as ferramentas digitais ou explorando novas práticas de ensino. É certo que isso não exime o poder público e gestores de suas responsabilidades perante essa situação. Como nos ensina a curadora e ativista guatemalense Lorena Cabnal (2019): "recupero la alegría sin perder la indignación, como un acto emancipatorio y vital"!

Assim, terminamos com as questões instigantes do educador português António Nóvoa (2020, p. 11):

A pandemia coloca-nos perante opções decisivas: vamos ter a coragem colectiva de assumir a educação pública como a prioridade das prioridades ou vamos deixar a educação ao cuidado, e ao serviço, de grupos privados e de plataformas digitais? Vamos valorizar os professores e o seu papel como profissionais autonómos e independentes ou vamos transformá-los em meros aplicadores ou acompanhadores dos conteúdos digitais? Vamos enriquecer a acção das escolas públicas como lugar de encontro entre todas as pessoas, independentemente das suas origens e condição, ou vamos levar toda a educação para espaços domésticos e privados? Que sociedade queremos? Que escola queremos? Que futuro queremos?

Afinal de contas, “o 'futuro' se escreve no presente" (REZENDE; FREIRE, 2020, p. 182). 


\section{REFERÊNCIAS}

A FOLHA. Educação de MT enfrenta pandemia com tecnologia e valoriza professores. 2021. Disponível em: https://www.afolhanoticias.com.br/noticia/679/Educa\%C3\%A7\%C3\%A3o-de-MT-enfrenta-pandemia-comtecnologia-e-valoriza-professores Acesso em: 15 jun 2021.

AGÊNCIA SENADO. Pandemia acentua deficit educacional e exige ações do poder público. 2021. Disponível em: https://www12.senado.leg.br/noticias/infomaterias/2021/07/pandemia-acentua-deficit-educacional-e-exigeacoes-do-poder-publico Acesso em: 16 jul 2021.

AMERICAS QUARTELY. Back to the 1960s? Education May Be Latin America's Most Lasting Scar from COVID-19. 2021. Disponível em: https://www.americasquarterly.org/article/back-to-the-1960s-education-maybe-latin-americas-most-lasting-scar-from-covid-19/ Acesso em 15 jun 2021.

ANDRÉ, M. Formação de professor: a constituição de um campo de estudos. Educação, v. 33, n. 3, p. 174-181, 2010.

BRASIL. Diário Oficial da União: Atos do Poder Legislativo. Portaria $n^{\circ}$ 356, de 11 de março de 2020. $n^{\circ} 49$, quinta-feira, 12 de março de 2020.

BRASIL DE FATO. Desigualdade no acesso à internet criou "elite estudantil" no Brasil da pandemia. 2021. Disponível em: https://www.brasildefato.com.br/2021/06/15/desigualdade-no-acesso-a-internet-criou-eliteestudantil-no-brasil-da-pandemia Acesso em: 15 jun 2021.

CABNAL, L. Entrevista concedida a Florencia Goldsman. Pikara Magazine, 13 nov 2019. Disponível em: https:// www.pikaramagazine.com/2019/11/lorena-cabnal-recupero-la-alegria-sin-perder-la-indignacion-como-un-actoemancipatorio-y-vital/ Acesso em: 15 set 2021.

CHIZZOTTI, A. Pesquisa qualitativa em ciências humanas e sociais. Petrópolis: Vozes, 2011.

DENZIN, N. K.; LINCOLN, Y. S. A disciplina e a prática da pesquisa qualitativa. In: (orgs.). $\mathbf{O}$ Planejamento da pesquisa qualitativa: teorias e abordagens. Porto Alegre: Artmed, 2006, p. 15-41.

DIESEL, A.; BALDEZ, A. L. S.: MARTINS, S. N. Os princípios das metodologias ativas de ensino: uma abordagem teórica. Revista Thema. v.14. n.1, p. 268-288, 2017.

FOLHA DE SÃO PAULO. Segundo IBGE, 4,3 milhões de estudantes brasileiros entraram na pandemia sem acesso à internet. 2021. Disponível em: https://www1.folha.uol.com.br/educacao/2021/04/segundo-ibge-43milhoes-de-estudantes-brasileiros-entraram-na-pandemia-sem-acesso-a-internet.shtml Acesso em: 15 jun 2021.

FREIRE, P. Pedagogia da Autonomia: Saberes Necessários à Prática Educativa. São Paulo: Editora Paz e Terra. Coleção Saberes. 1996.

FUNDAÇÃO CARLOS CHAGAS. Pesquisa: Educação escolar em tempos de pandemia na visão de professoras/ es da Educação Básica. Informe nº 1. Departamento de Pesquisas Educacionais. 2020.

GOBATTO, M. R.; BERALDO, T. M. A construção do Centro de Formação e Atualização dos Profissionais da Educação Básica de Mato Grosso como política de Estado. Educação em Perspectiva, v. 5, n. 1, 15 jul. 2014.

IPEA. Políticas Sociais: acompanhamento e análise. BPS - Educação, n. 28, 2021. DOI: http://dx.doi. org/10.38116/bps28/educacao

MACEDO, R. M. Direito ou privilégio? Desigualdades digitais, pandemia e os desafios de uma escola pública. Estudos Históricos, Rio de Janeiro, v. 34, n. 73, p. 262-280, Maio-Agosto 2021. DOI: https://doi.org/10.1590/ S2178-149420210203

MATO GROSSO. Secretaria de Educação e Cultura. Decreto no 2.007/1997. Cuiabá: Seduc, 1997.

MATO GROSSO. Secretaria de Educação e Cultura. Portaria no 02/1998. Cuiabá: Seduc, 1998.

MORAN, J. Metodologias ativas para uma aprendizagem mais profunda. In: BACICH, L. J.; MORAN, J. (Org). Metodologias ativas para uma educação inovadora: uma abordagem teórico prática. Porto Alegre, Artmed, 2018. p. 1-25.

NÓVOA, A. Os professores e o "novo" espaço público da educação. In: TARDIF M.; LESSARD, C. (Org.) O ofício de professor: história, perspectivas e desafios internacionais. 6 ed. Petrópolis (RJ): Vozes, 2014, p. 217-233. 
NÓVOA, A. A pandemia de Covid-19 e o futuro da Educação. Revista Com Censo \#22. v. 7, n. 3, p. 8-12, ago 2020.

REZENDE, T. F.; FREIRE, S. M. "O 'futuro' se escreve no presente”. In: MESQUITA, D. N. de C. (Org.) Escola de educação básica para todos: volume V. Editora Espaço Acadêmico, Goiânia, 2020, p. 182-192.

SAVIANI, D. O pensamento pedagógico brasileiro: da aspiração à ciência à ciência sob suspeição. Educação $\mathrm{e}$ Filosofia, v.21, n.42, p. 13-35, 2007.

TREZZI, C. A educação pós-pandemia: uma análise a partir da desigualdade educacional. Dialogia, São Paulo, n. 37, p. 1-14, e18268, jan./abr. 2021. Disponível em: https://doi.org/10.5585/dialogia.n37.18268

WORLD HEALTH ORGANIZATION. WHO Director-General's opening remarks at the media briefing on COVID-19. 11 de março de 2020. Disponível em: www.who.int/dg/speeches/detail/who-director-general-sopening-remarks-at-the-media-briefing-on-covid-19---11-march-2020 Acesso em: 08 jul 2020. 